\title{
DEVELOPMENT AND CHARACTERIZATION OF TACROLIMUS TABLET FORMULATIONS FOR SUBLINGUAL ADMINISTRATION
}

\author{
JISHA MOHANAN ${ }^{1}$, SEENIVASAN PALANICHAMY ${ }^{2}$, ARUL KUTTALINGAM ${ }^{3}$, DAMODHARAN NARAYANASAMY ${ }^{4}$
}

${ }^{1}$ College of Pharmaceutical Sciences, Government Medical College, Kozhikode 673008, Kerala, India, ${ }^{2}$ Sri Ramachandra Faculty of

Pharmacy, Sri Ramachandra Institute of Higher Education and Research, Porur, Chennai 600116, Tamil Nadu, India, ${ }^{3}$ College of

Pharmaceutical Sciences, Government Medical College, Kottayam 686008, Kerala, India, ${ }^{4}$ SRM College of Pharmacy, SRM University, Kattankulathur 603203, Tamil Nadu, India

*Email: seenumelur@gmail.com

Received: 15 Jun 2021, Revised and Accepted: 19 Aug 2021

\section{ABSTRACT}

Objective: The study aimed to prepare and characterize inclusion complexes of tacrolimus with $\beta$-cyclodextrin to improve its solubility and to formulate them into sublingual fast disintegrating tablets with a view to bypass the first-pass metabolism.

Methods: Tacrolimus: $\beta$-cyclodextrin inclusion complexes (1:1 and 1:2 molar proportions) were prepared using the kneading method. Their characterization was accomplished by determining the drug content, solubility, Attenuated Total Reflection-Infrared Spectroscopy (ATR-IR), Scanning Electron Microscopy (SEM), Differential Scanning Calorimetry (DSC), and powder X-Ray Diffraction analysis (pXRD). These were then formulated to fast disintegrating tablets and evaluated for precompression as well as post compressional characteristics.

Results: SEM analysis showed the inclusion complexes as rough, non-porous, irregular surfaced aggregate particles. DSC and pXRD analyses confirm the crystallinity change and partial conversion to the amorphous form of the drug in the inclusion complexes. From the solubility studies, it was observed that both the inclusion complexes of $1: 2$ molar ratio $(14.82 \pm 0.889 \mu \mathrm{g} / \mathrm{ml})$ and $1: 1$ molar ratio $(12.72 \pm 0.1004 \mu \mathrm{g} / \mathrm{ml}) \mathrm{improved}$ the aqueous solubility to greater extents in comparison to that of the pure drug $(3.05 \pm 0.121 \mu \mathrm{g} / \mathrm{ml})$. All the tablet formulations showed good precompression and mechanical properties. The inclusion complex loaded tablets exhibited a superior drug release pattern when compared to tablets prepared with tacrolimus alone. The optimized formulation (TT3) showed an in vitro disintegration time of $34.33 \mathrm{~s}$ and a percent drug release of 97.87.

Conclusion: The inclusion complex formulation combined with the sublingual route of administration can be expected to result in an improved bioavailability of tacrolimus by increasing its solubility and bypassing first-pass metabolism.

Keywords: Tacrolimus, $\beta$-Cyclodextrin, Inclusion complex, Kneading, Solubility, Sublingual tablet, Fast disintegrating

(C) 2021 The Authors. Published by Innovare Academic Sciences Pvt Ltd. This is an open access article under the CC BY license (https://creativecommons.org/licenses/by/4.0/) DOI: https://dx.doi.org/10.22159/ijap.2021v13i6.42429. Journal homepage: https://innovareacademics.in/journals/index.php/ijap

\section{INTRODUCTION}

Tacrolimus, one among the calcineurin inhibitors, is a lipophile 23member macrolide-based lactone having strong immunosuppressive characteristics $[1,2]$. Nowadays, it stands in the top position as the most widely used immunity suppressor and has revealed a new era in the biggest problem of rejection in organ transplantation. The drug is used for the prophylaxis of organ rejection, including liver, kidney and heart and in the case of allograft rejections resistant to other immunosuppressants [3].

Mostly, oral and intravenous routes are currently used for its administration. Limitations of the intravenous route are high probabilities of neuro and nephro toxicities. Orally administered tacrolimus has poor bioavailability $(\sim 21 \%)$ issues [4] due to a plethora of reasons like poor solubility, high permeability, profound first-pass metabolism in gut and liver, the influence of food intake and concomitant medication [5].

Tacrolimus comes under Biopharmaceutics Classification System (BCS) class II, having low solubility and high permeability [6]. To increase the solubility of tacrolimus, diverse types of oral-based tacrolimus preparations were developed, namely nanoparticles [7], prodrug of poly(ethylene glycol) esters [8], and solid sodium carboxyl methyl cellulose dispersions as well as aminoalkyl methacrylates based solid dispersions $[1,9,10]$.

In the area of solubility improvement, complexing with $\beta$ cyclodextrins has gained much importance with the accumulation of poorly water-soluble drugs. Studies have shown that solid inclusion complexes prepared with $\beta$-cyclodextrins can substantially upsurge the water solubility and bioavailability of lipophilic drugs [11].

But in the case of tacrolimus, application of the inclusion complex technique can resolve the poor aqueous solubility problem, but not the first pass metabolic problem. Therefore, the inclusion complex technique combined with an alternative route of administration i.e. the highly vascularised sublingual route of administration, may further improve the bioavailability of tacrolimus by circumventing the first-pass metabolism in the gut and liver. There are clinical studies to prove that sublingual tacrolimus is comparable to or more effective than oral administration, concerning bioavailability, in solid organ transplant patients [12-14].

Potential advantages of the sublingual route include good permeability, rapid absorption, acceptable bioavailability, and faster onset of action. Additionally, due to increased bioavailability, the dosage can be reduced, which may further result in lower medical costs of a comparatively costlier drug, like tacrolimus. It might be an alternate route for patients who cannot swallow the oral dose form, for example, intubated transplant recipients [15].

The present work attempted to develop inclusion complexes of tacrolimus with $\beta$-cyclodextrin by employing the kneading technique and to further formulate them into fast disintegrating tablets for sublingual administration to improve solubility and bioavailability of the drug.

\section{MATERIALS AND METHODS}

\section{Materials}

The drug tacrolimus monohydrate was procured from Yarrowchem, Mumbai, India. $\beta$-cyclodextrin was purchased from the Sisco Research Laboratories, Croscarmellose sodium (CCS), Sodium starch glycolate (SSG) and Mannitol from Astron chemicals, Ahmedabad, India, Cellulose microcrystalline (MCC), Talc, Citric acid and Magnesium stearate from Loba Chemie, Mumbai, India, and methanol was purchased and Kanton Laboratories. 


\section{Methods}

\section{Preparation of tacrolimus inclusion complexes}

The tacrolimus and $\beta$-cyclodextrin complexes were formulated using the two molar ratios, $1: 2$ and $1: 1$, respectively. The calculated amounts of tacrolimus and $\beta$-cyclodextrin were precisely weighed and triturated with small amounts of a mixed solution of $1: 1(\mathrm{v} / \mathrm{v})$ methanol: water in a glass mortar until a thin slurry was obtained. Furthermore, the slurry was kneaded thoroughly for around $40 \mathrm{~min}$. After the evaporation of the solvents, the complexes were dried at room temperature for a period of $1 \mathrm{~d}$ and stored in a desiccator [16].

\section{Assessment of inclusion complexes}

\section{High performance liquid chromatography (HPLC) analytical method}

The estimation of tacrolimus in the samples was done by the HPLC method according to USP. The instrument model used was HPLC Agilent 1260 infinity. The mobile phase was constituted from different compositions of $6 \mathrm{mmol}$ phosphoric acid and acetonitrile and tertiary butyl methyl ether (81:19). The diluent used was acetonitrile and water $(7: 3)$. Both the standard and sample solutions were allowed to stand for $3 \mathrm{~h}$ at room temperature, protected from light. The column employed was of dimension $15 \mathrm{~cm} \mathrm{X} 4.6 \mathrm{~mm}$ and the column temperature, $60^{\circ} \mathrm{C} .20 \mu \mathrm{l}$ of injection volumes were used and the eluents were examined at $220 \mathrm{~nm}$ by a stream rate of 1.5 $\mathrm{ml} /$ minute [17].

Linearity was confirmed by plotting the calibration graph and the data obtained were analyzed by regression analysis to find out correlation coefficient and calibration equation.

\section{Drug content}

$20 \mathrm{mg}$ of the solid complex is dissolved in $10 \mathrm{ml}$ of methanol in a standard flask and it was sonicated for a period of $3 \mathrm{~h}$ and then centrifuged at $3000 \mathrm{rpm}$ for $10 \mathrm{~min}$. The obtained supernatant was strained over a membrane filter with a size of $0.45 \mu \mathrm{m}$ was then analyzed for the drug content via HPLC. Measurements were done in triplicate and the data were expressed as mean and standard deviation (SD).

\section{Solubility investigation}

To check the influence of formulation into inclusion complex on the aqueous solubility of drug, solubility assessments were done by shake flask method. An excess amount of drug as well as tacrolimus$\beta$-cyclodextrin complexes was introduced to $5 \mathrm{ml}$ of distilled water and in a shaking water bath, it was shaken for $1 \mathrm{~h}$. Further, the solution was centrifuged at $3000 \mathrm{rpm}$ for $10 \mathrm{~min}$ and the supernatant was strained over a membrane filter with a size of 0.45 $\mu \mathrm{m}$ which is further analyzed for drug content by HPLC. The procedure was repeated three times and the mean and SD was calculated [18].

\section{ATR-IR analysis}

ATR-IR spectroscopy is a sampling method utilized besides the traditional infrared spectroscopy. Jasco FT/IR 4700 spectrophotometer was used to record the infrared spectrum of pure medicine, inert ingredients, physical mixture and developed complexes. ATR mode-IR spectra were taken employing a scanning scale of 400 and $4000 \mathrm{~cm}^{-1}$.

\section{SEM study}

The surface morphology of the prepared complexes was studied by SEM (model: Hitachi SU 6600). Specimens were placed in a brass sample stub employing both-sided adhesive carbon tape and the samples were made electrically conductive by gold sputtering within the vacuum utilizing the Hitachi sputter for a time of $300 \mathrm{~s}$ at $15 \mathrm{~mA}$.

\section{DSC analysis}

Thermal features of pure tacrolimus, drug-carrier mixture, and prepared complexes were analyzed by DSC apparatus (Q20 TA instruments). About $10-12 \mathrm{mg}$ of sample in a sealed aluminium standard pan was heated at a scanning rate of $10^{\circ} \mathrm{C} / \mathrm{min}$ from room temperature to $225^{\circ} \mathrm{C}$ under nitrogen gas flow.

\section{pXRD study}

pXRD studies were performed to evaluate any change in crystallinity of the drug in the complexes (equipment model: Bruker model D8 Advance). Specimens of tacrolimus drug powder, its physical mixture with the carrier and tacrolimus- $\beta$-cyclodextrin complexes were analyzed at $25^{\circ} \mathrm{C}$ utilizing monochromatic $\mathrm{Cu} \mathrm{K}$-radiation at 40 $\mathrm{mA}$ and $40 \mathrm{kV}$ within the region of $2.5^{\circ} \leq 2 \theta \leq 40^{\circ}$ in continuous scan mode with a step size of $0.02^{\circ}$.

\section{Formulation of inclusion complex loaded sublingual tablets}

The inclusion complex (tacrolimus and $\beta$-cyclodextrin in 1:2 molar ratio) was further formulated to sublingual tablets by direct compression method. $100 \mathrm{mg}$ weighing $7 \mathrm{~mm}$ tablets containing inclusion complexes equivalent to $1 \mathrm{mg}$ of the drug were compressed in a 16 station Cadmach rotary tablet compression machine. To aid the fast disintegration of the tablets, two disintegrating agents were employed, SSG and CCS at different concentrations [19, 20]. Magnesium stearate was used as the lubricant, talc as a glidant, mannitol as sweetener, citric acid as saliva stimulating agent as well as to improve the mouthfeel and the diluent used was MCC.

Six tablet formulations were developed (TT1-TT6) with inclusion complexes of tacrolimus and one batch of tablets (TT0) containing 1 $\mathrm{mg}$ of pure tacrolimus drug was also formulated. The composition of various formulations is presented in table 1 .

Table 1: Composition of sublingual tablet formulations

\begin{tabular}{|c|c|c|c|c|c|c|c|}
\hline Ingredients (mg) & TT 1 & TT2 & TT3 & TT4 & TT 5 & TT 6 & TT0 \\
\hline Complex equivalent to $1 \mathrm{mg}$ drug & 1.99 & 1.99 & 1.99 & 1.99 & 1.99 & 1.99 & -- \\
\hline Drug alone & -- & -- & -- & -- & -- & -- & 1 \\
\hline CCS & 8 & 10 & 12 & -- & -- & -- & 12 \\
\hline SSG & & & & 4 & 6 & 8 & - \\
\hline Magnesium stearate & 1.5 & 1.5 & 1.5 & 1.5 & 1.5 & 1.5 & 1.5 \\
\hline Talc & 1 & 1 & 1 & 1 & 1 & 1 & 1 \\
\hline Mannitol & 12 & 12 & 12 & 12 & 12 & 12 & 12 \\
\hline Citric acid & 1.25 & 1.25 & 1.25 & 1.25 & 1.25 & 1.25 & 1.25 \\
\hline MCC & q. s $100 \mathrm{mg}$ & q. s $100 \mathrm{mg}$ & q. s $100 \mathrm{mg}$ & q. s $100 \mathrm{mg}$ & q. s $100 \mathrm{mg}$ & q. s $100 \mathrm{mg}$ & q. s $100 \mathrm{mg}$ \\
\hline
\end{tabular}

\section{Pre compressional studies}

The prepared powder blends of all the formulations were subjected to preformulation evaluations like poured density, tapped density, angle of repose, Carr's compressibility index and Hausner ratio [21].

\section{Post compressional evaluation}

The prepared tablets were evaluated for the following tests [22].

\section{Weight variation}

A standard weight variation test was performed. 20 tablets were accurately weighed and the percentage weight variation was determined as per official standards.

\section{Thickness}

Thickness measurements were done by using a micrometer. 6 randomly selected tablets from each formulation were used. Found out mean and SD. 


\section{Hardness}

A Monsanto hardness tester was used to measure the hardness of tablets. 6 tablets were used from each batch of the formulation. The average value and SD were calculated.

\section{Friability}

Friability was performed with 20 tablets in Roche's friabilator revolving at $25 \mathrm{rpm}$ for $4 \mathrm{~min}$. The average value and SD were determined.

\section{Wetting time and water absorption ratio (WR)}

A doubly folded tissue paper piece was placed at the center of a $10 \mathrm{~cm}$ diameter Petri plate and $6 \mathrm{ml}$ of phosphate buffer $\mathrm{pH} 6.8$ (containing a dye for easy visibility) was poured to wet the paper, excess of the buffer was completely drained out of the plate. A preweighed tablet (weight, W1) was placed at the center of the paper and allowed to wet. The time required for the buffer to diffuse from the wetted paper throughout the entire tablet (wetting time) was recorded $[23,24]$. The wetted tablet was weighed (W2) and the WR was determined using the following equation:

$$
\frac{(\mathrm{W} 2-\mathrm{W} 1)}{\mathrm{W} 1} \times 100
$$

Where W2 = Weight of tablet after water absorption

\section{W1 = Weight of tablet before water absorption}

\section{In vitro disintegration time}

To assess the disintegration time, the method described by Mutasem et al. was modified and followed. The tablets were placed in a beaker ( $3 \mathrm{~cm}$ diameter) containing $10 \mathrm{ml}$ of phosphate buffer $\mathrm{pH} 6.8$, the beaker was gently rotated and the time for the tablets to completely disintegrate was determined [25].

\section{Uniformity of content}

This test was done based on the assay of the individual drug content of 10 tablets by the HPLC method. They were separately dissolved in $10 \mathrm{ml}$ methanol and then $1 \mathrm{ml}$ solution was diluted to $10 \mathrm{ml}$ with methanol and filtered with $0.45 \mu \mathrm{m}$ membrane filter [26]. The tacrolimus content was estimated by the HPLC method as described in inclusion complex drug estimation. The average tacrolimus content and SD were found out.

\section{In vitro drug dissolution studies}

Dissolution studies were performed in IP dissolution apparatus I (paddle) employing $250 \mathrm{ml}$ of phosphate buffer $\mathrm{pH} 6.8$ containing $0.5 \% \mathrm{w} / \mathrm{v}$ sodium lauryl sulphate as the dissolution medium and was maintained at $37^{\circ} \mathrm{C}$ with paddle speed set at $50 \mathrm{rpm}[27,28]$.

The samples, $3 \mathrm{ml}$, were manually withdrawn at each time point; syringe filtered and was then replaced by fresh dissolution medium. The samples were analyzed by HPLC. Measurements were conducted in triplicate and the amounts of drug dissolved are calculated as average percentages with SD.

\section{RESULTS AND DISCUSSION}

\section{Analytical data}

Under standard analytical conditions, the optimal features and the statistical characteristics of the HPLC technique were examined. The calibration plot is shown in fig. 1 . The linearity range was from 0.05 to 0.25 weight percentage. From the graph, it was identified that the correlation coefficient value was 0.999 . Moreover, the retention of tacrolimus monohydrate was found to be $1.657 \pm 0.005 \mathrm{~min}$ and the peak area, $22098 \pm 219.7$, with the wavelength of detection at $220 \mathrm{~nm}$ as shown in fig. 2 . The estimations were done in triplicate.

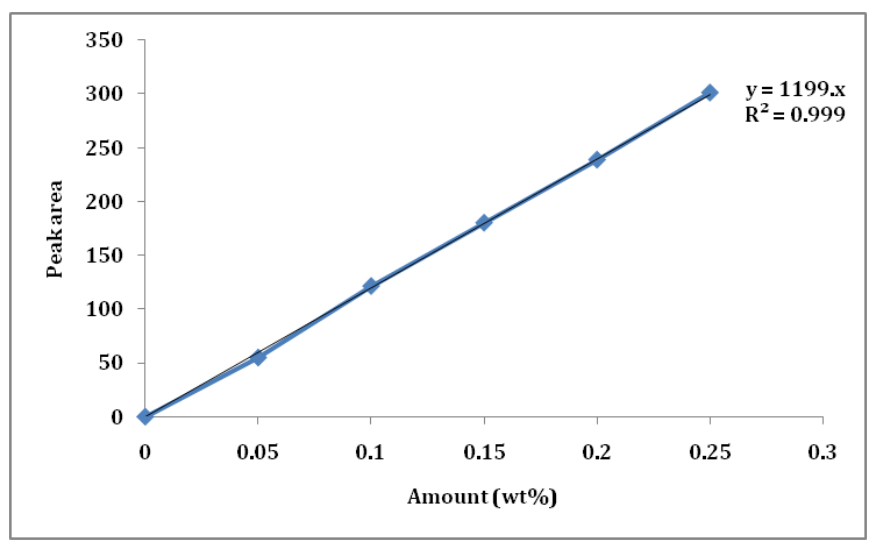

Fig. 1: HPLC calibration curve of tacrolimus monohydrate

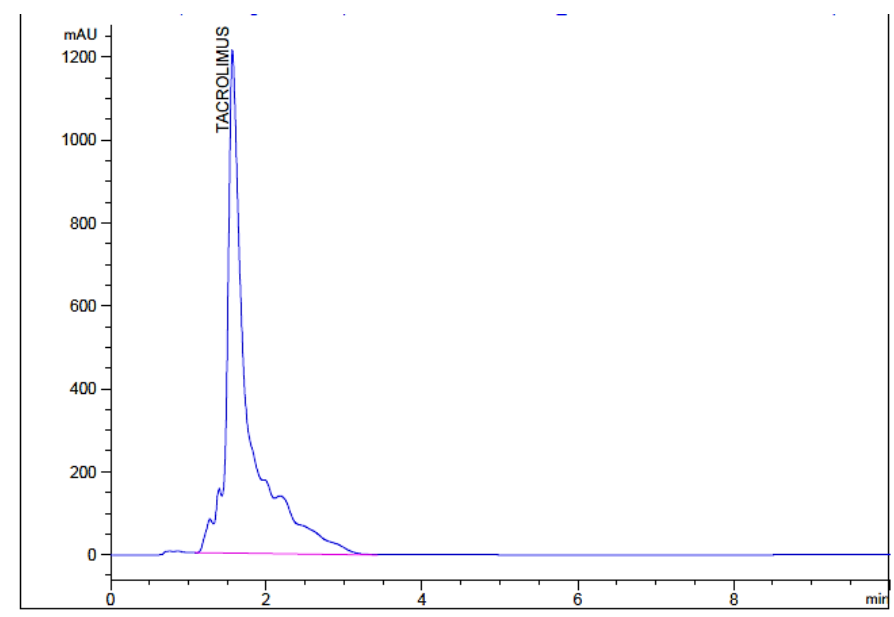

Fig. 2: A sample HPLC peak of tacrolimus monohydrate 


\section{Characterization studies of inclusion complexes}

\section{Drug content}

Complexes prepared in the 1:1 molar ratio (drug: $\beta$-cyclodextrin) exhibited a \% drug content of 97.65 whilst the complex with 1:2 molar ratio, 96.84 (table 2). Thus, it can be stated that the drug tacrolimus was evenly dispersed in the complex formulation by the kneading technique employed.

\section{Solubility investigation}

One of the aims of this research was to improve the solubility of the practically insoluble tacrolimus by the inclusion complex approach. The aqueous solubility of the pure drug was determined as $3.05 \pm 0.121 \mu \mathrm{g} / \mathrm{ml}$ and those of complexes prepared in $1: 2$ and $1: 1$ molar ratios were found to be $14.82 \pm 0.889 \mu \mathrm{g} / \mathrm{ml}$ and $12.72 \pm 0.1004$ $\mu \mathrm{g} / \mathrm{ml}$ respectively (table 2 ). So, it can be seen that the complexation of tacrolimus with $\beta$-cyclodextrin led to the enhancement of aqueous solubility to higher extents in comparison to the pure drug, i.e., more than four times. Eventually, the complexes prepared in the $1: 2$ ratio enhanced the solubility to superior values in comparison to the $1: 1$ complex, which may be because the lower amount of $\beta$-CD in 1:1 molar complexes resulted in decreased complexation and hence, lower solubility improvement.

\section{ATR-IR analysis}

IR spectra in the ATR mode were taken in the range from 400-4000 $\mathrm{cm}^{-1}$ and the obtained spectra for pure tacrolimus, $\beta$-cyclodextrin, the tacrolimus: $\beta$-cyclodextrin physical mixture and the complexes are shown in fig. 3. Tacrolimus monohydrate showed $\mathrm{O}-\mathrm{H}$ stretching vibration at $3,440 \mathrm{~cm}^{-1}, \mathrm{C}=0$ (ester as well as ketone) stretching vibrations at $1,739 \mathrm{~cm}^{-1}, \mathrm{C}=0$ (keto-amide) and $\mathrm{C}=\mathrm{C}$ stretch peaks at $1,637 \mathrm{~cm}^{-1}, \mathrm{C}-\mathrm{O}$ (ester) stretching vibration at $1,170 \mathrm{~cm}^{-1}$ and $\mathrm{C}-\mathrm{O}-\mathrm{C}$ (ether) stretching vibrations at $1,084 \mathrm{~cm}^{-1}$. No much variation in the peaks was observed in the case of the spectrum of tacrolimus: $\beta$ cyclodextrin physical mixture. On the examination of spectra of the formulated complexes, the following findings were noted. The absorption bands at 3,440, 1739 and $1637 \mathrm{~cm}^{-1}$ were somewhat weakened and these outcomes propose that the $\mathrm{C}=\mathrm{O}$ and $\mathrm{O}-\mathrm{H}$ functional assemblies of tacrolimus monohydrate have interacted at a molecular level in the inclusion complexes.

Table 2: Drug content and aqueous solubility of tacrolimus/prepared complexes

\begin{tabular}{lll}
\hline Drug/inclusion complex & Drug content $(\% \mathbf{w} / \mathbf{w})$ & Aqueous solubility $(\boldsymbol{\mu g} / \mathbf{m l})$ \\
\hline Tacrolimus & $-96.84 \pm 1.76$ & $3.05 \pm 0.1210$ \\
$1: 2$ complex & $97.65 \pm 1.29$ & $14.82 \pm 0.8890$ \\
$1: 1$ complex & $92.72 \pm 0.1004$ \\
\hline
\end{tabular}

${ }^{*}$ Data are expressed as mean $\pm \mathrm{SD}(\mathrm{n}=3)$

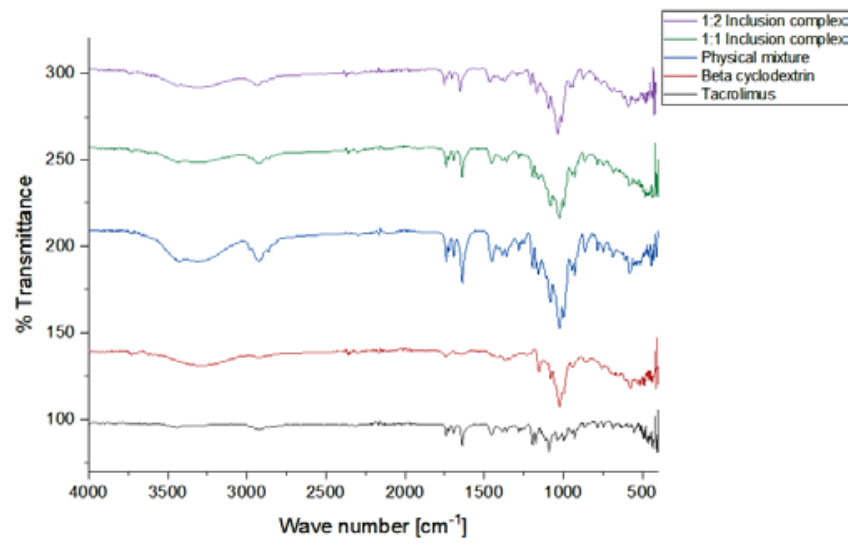

Fig. 3: ATR-IR spectra of tacrolimus monohydrate, $\beta$-cyclodextrin, physical mixture of tacrolimus monohydrate and $\beta$-cyclodextrin, inclusion complex 1:1 ratio and inclusion complex 1:2 ratio

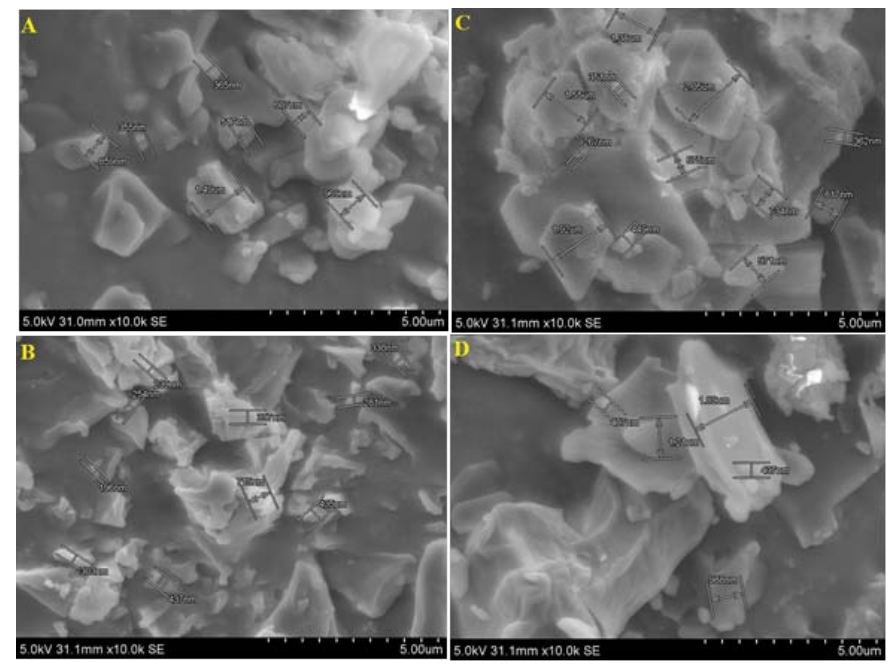

Fig. 4: SEM (A) tacrolimus monohydrate (B) $\beta$-cyclodextrin (C) inclusion complex 1:1 (D) inclusion complex 1:2 


\section{SEM analysis}

SEM images of tacrolimus, $\beta$-cyclodextrin, solid complexes in the proportion of $1: 2$ and $1: 1$ are shown in fig. 4 . From fig. $4 \mathrm{~A}$, it can be seen that tacrolimus appeared as smoother-surfaced rectangular crystals. $\beta$-cyclodextrin appeared as irregular-shaped crystals (fig. $4 \mathrm{~B})$. Both the inclusion complexes were found to appear as rough, non-porous, irregular surfaced aggregates (fig. 4C and fig. 4D). Since it was not possible to identify the crystals of individual drug and carrier, it could be assumed that both the components interacted well during the formation of complexes.

\section{DSC study}

The thermal behaviour of tacrolimus, physical mixture and inclusion-complexes of the proportion of $1: 2$ and $1: 1$ molar ratios were assessed and are presented in fig. 5. DSC of pure tacrolimus showed a broad endothermic event attributed to dehydration occurring at temperatures between $75{ }^{\circ} \mathrm{C}$ and $122{ }^{\circ} \mathrm{C}$ followed by melting of the anhydrate form with a sharp endothermic peak at $129.46{ }^{\circ} \mathrm{C}$ which corresponds to its melting point and indicating its crystalline nature. DSC of the physical mixture also showed peaks of tacrolimus as well as an additional peak of $\beta$-cyclodextrin. DSC of both complexes showed that the sharp peak corresponding to the drug was broadened and reduced in intensity, which indicated the formation of inclusion complexes and partial conversion to amorphous form.

\section{pXRD studies}

pXRD analysis was done to evaluate any change in crystallinity of the drug in the formulated complexes. Fig. 6 displays the pXRD spectra of a) tacrolimus b) physical mixture c) inclusion complexes of 1:1 molar ratio as well as d) for 1:2 molar ratios, respectively. Tacrolimus showed intense diffraction bands of crystalline nature at $2 \theta$ values between 8.5 and 23 , therefore, is present as a crystalline material. The physical mixture also showed crystalline peaks of the drug in the same regions. X-ray diffraction pattern of inclusion complexes exhibited a reduction in the intensity of large diffraction peaks indicating a decrease in crystallinity or partial conversion into an amorphous form of the drug. This slight conversion to amorphous nature was also confirmed in DSC data interpretation and it was assumed that this could also contribute to the enhanced solubility of the complexes apart from the influence of inclusion complex formation with the carrier, $\beta$-cyclodextrin.
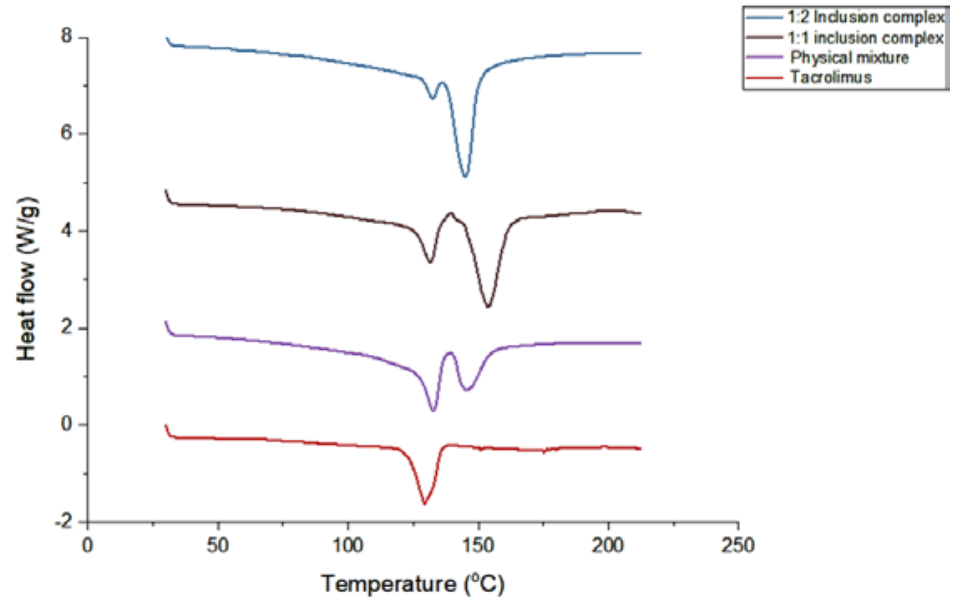

Fig. 5: DSC thermogram of tacrolimus monohydrate, physical mixture of tacrolimus monohydrate and $\beta$-cyclodextrin, inclusion complex 1:1, inclusion complex 1:2

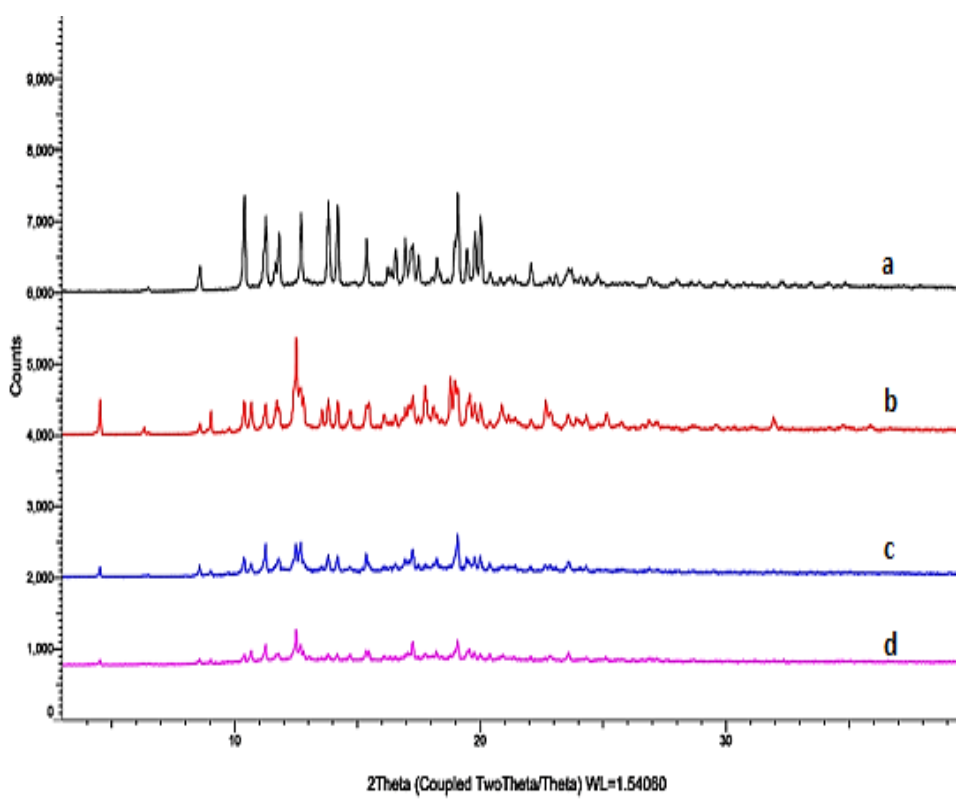

Fig. 6: Powdered X-ray diffraction spectra of (a) tacrolimus monohydrate (b) Physical mixture of tacrolimus monohydrate and $\beta$ cyclodextrin (c) inclusion complex 1:1 (d) inclusion complex 1:2 
Table 3: Micromeritic studies of powder blends

\begin{tabular}{|c|c|c|c|c|c|}
\hline Formulation code & Poured density & Tapped density & Angle of repose & Carr's compressibility index & Hausner ratio \\
\hline TT 1 & $0.318 \pm 0.0078$ & $0.374 \pm 0.0152$ & $30.84 \pm 1.55$ & $14.97 \pm 0.80$ & $1.18 \pm 0.0125$ \\
\hline TT 2 & $0.309 \pm 0.0080$ & $0.355 \pm 0.0141$ & $29.03 \pm 3.71$ & $12.96 \pm 0.73$ & $1.15 \pm 0.0138$ \\
\hline TT 3 & $0.327 \pm 0.0077$ & $0.388 \pm 0.0155$ & $31.82 \pm 1.44$ & $15.72 \pm 0.87$ & $1.19 \pm 0.0098$ \\
\hline TT 4 & $0.316 \pm 0.0071$ & $0.380 \pm 0.0153$ & $30.34 \pm 2.12$ & $16.84 \pm 0.81$ & $1.20 \pm 0.0141$ \\
\hline TT 5 & $0.309 \pm 0.0082$ & $0.351 \pm 0.0140$ & $28.84 \pm 1.99$ & $11.97 \pm 0.87$ & $1.14 \pm 0.0133$ \\
\hline TT 6 & $0.315 \pm 0.0079$ & $0.360 \pm 0.0172$ & $27.13 \pm 2.01$ & $12.50 \pm 0.80$ & $1.14 \pm 0.0129$ \\
\hline TT 0 & $0.321 \pm 0.0084$ & $0.362 \pm 0.0165$ & $29.11 \pm 1.21$ & $11.33 \pm 0.80$ & $1.13 \pm 0.0132$ \\
\hline
\end{tabular}

*Data are expressed as mean \pm SD $(n=3)$

\section{Development of sublingual tablets of tacrolimus}

For the development of sublingual tablets, the inclusion complex prepared in the molar ratio of 1:2 was selected as it enhanced the solubility of tacrolimus to higher values than the complex prepared in the 1:1 ratio. After the preparation and complete evaluation of tablets containing inclusion complexes (TT1-TT6, see table 1), tablets of the pure drug (TT0) were also formulated with the excipient composition of TT3 as it was found to have better disintegration and dissolution characteristics.

\section{Preformulation studies of tablets}

The powder blends of all the formulation batches showed good flow properties and compressibility characteristics. The results obtained with preformulation powder properties are presented in table 3 . The flow characteristics obtained ranged between 27.13 and 31.82 for the angle of repose which suggested good to excellent flow characteristics of the blend. Carr's compressibility indices were between 11.33 and 16.84, indicating good to excellent flow properties and for the Hausner ratio, the values were between 1.13 and 1.20 which also assured good flow.

\section{Characterization of sublingual tablets}

Sublingual tablets were prepared by direct compression.

\section{Mechanical properties}

The results of the mechanical properties of the prepared tablets are presented in table 4 . For tablets with an average weight of 80-250 mg the percentage deviation allowed is below $7.5 \%$ as per IP. It was observed that all the tablet formulations fulfilled this specification, as the percentage of weight variation was within the pharmacopoeial limits [29]. The tablets were all of almost uniform thickness ranging between 3.51 and $3.53 \mathrm{~mm}$.

All the tablets possessed sufficient mechanical strength, with hardness between 2.36 and $2.95 \mathrm{~kg} / \mathrm{cm}^{2}$. The tablet strengths were also measured by determining friability and the values ranged from 0.681 and 0.993 which were within the acceptable limit (i.e., $<1 \%$ ), also indicating that the prepared tablets were all mechanically sound.

\section{Wetting evaluation}

The procedure for wetting pattern evaluation mimics the action of saliva when it comes in contact with tablets and thus gives an understanding of the disintegration behavior of the tablets in the sublingual oral cavity. Wetting time was slightly higher for tablets prepared with CCS (24.45-29.58 s) than with SSG (14.35-16.23 s). This slightly higher water uptake rate of SSG could be attributed to their smaller particle size and higher amorphous content which eased water accessibility. The wetting times and WR of the tablets are given in table 5 . The WR ranged between 148.50 to $162.48 \%$ for CCS-based tablets and 109.43 to 121.55 for SSG tablets. The high swelling ability of both CCS and SSG is ascribed to their ability to quickly hydrate and produce gels upon water uptake [30]. The wetting pattern of the tablet at various times is given in fig. 7 and it was observed that they swelled without losing their shape and their size increased on wetting.

Table 4: Mechanical properties of tablets

\begin{tabular}{llll}
\hline Formulation code & Weight variation $\mathbf{( m g )}(\mathbf{n = 2 0})$ & Thickness $(\mathbf{m m}) \mathbf{( n = 6 )}$ & Hardness $\left(\mathbf{K g} / \mathbf{c m}^{2}\right)(\mathbf{n = 6})$ \\
\hline TT 1 & $102.64 \pm 3.91$ & $3.51 \pm 0.01$ & $2.44 \pm 0.43$ \\
TT 2 & $102.13 \pm 4.35$ & $3.53 \pm 0.02$ & $2.86 \pm 0.54$ \\
TT 3 & $101.95 \pm 4.48$ & $3.52 \pm 0.03$ & $2.39 \pm 1.17$ \\
TT 4 & $102.47 \pm 3.64$ & $3.51 \pm 0.02$ & $2.95 \pm 0.93$ \\
TT 5 & $101.76 \pm 4.09$ & $3.52 \pm 0.01$ & $2.51 \pm 0.88$ \\
TT 6 & $102.32 \pm 4.49$ & $3.51 \pm 0.01$ & $2.36 \pm 0.44$ \\
TT 0 & $101.68 \pm 4.41$ & $3.52 \pm 0.01$ & $2.67 \pm 1.32$ \\
\hline
\end{tabular}

*Data are expressed as mean \pm SD

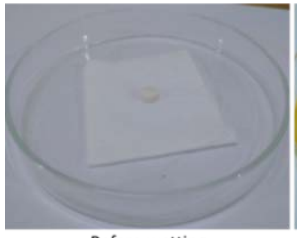

Before wetting

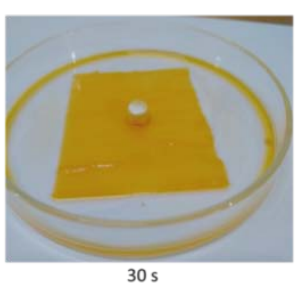

time

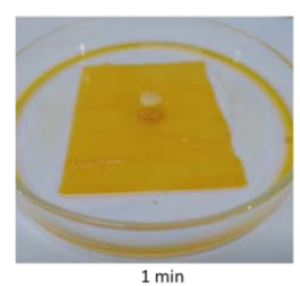

$1 \mathrm{~min}$

Fig. 7: Swelling of tablets at various periods 


\section{Disintegration studies (in vitro)}

As the tacrolimus tablets are intended to be used sublingually, fast disintegration is desirable so that the drug is released quickly and since the sublingual mucosa is highly permeable, the released drug will be absorbed rapidly. As the volume of saliva available for the tablet to disintegrate in the sublingual area is small, to mimic the sublingual condition, the disintegration test was done with a small volume i.e., 10 $\mathrm{ml}$ of the medium in a beaker. The disintegration times of tablets prepared with CCS as disintegrating agent ranged between $34.33 \mathrm{~s}$ and $79.17 \mathrm{~s}$ and were observed to be shorter than that of tablets with SSG (61.5 to $53 \mathrm{~s}$ ). The USP stipulates that a sublingual tablet should disintegrate within $2 \mathrm{~min}$; all the tablets met this requirement (table 5). For both SSG and CCS strong swelling is the main mechanism for promoting disintegration and in the case of SSG, the comparatively higher disintegration time may be attributed to the formation of a gel layer that delays disintegration [30].

\section{Uniformity of content}

Since the tablets contain less than $10 \mathrm{mg}$ of tacrolimus, uniformity of drug content was determined for each formulation of tablets. Only tacrolimus capsules are official in USP whose acceptance criteria are given as to contain NLT $93.0 \%$ and NMT $105.0 \%$ of the labelled amount of tacrolimus [31]. The mean percentage drug content of all the batches of tablets was found to be in the range of 95.52 to $101.56 \%$ (table 5). The values indicated uniform drug content within the tablets. Individual contents also were within the specified limits.

Table 5: Wetting time, WR, in vitro disintegration times and content uniformity of the prepared tablets

\begin{tabular}{|c|c|c|c|c|}
\hline Formulation code & Wetting time $(S)(n=3)$ & WR (\%) $(n=3)$ & In vitro disintegration time $(S)(n=6)$ & Uniformity of content $(\%)(n=10)$ \\
\hline TT 1 & $24.45 \pm 5.45 .45$ & $148.50 \pm 10.84$ & $79.17 \pm 7.22$ & $96.21 \pm 3.75$ \\
\hline TT 2 & $26.88 \pm 4.95$ & $153.77 \pm 14.61$ & $53.00 \pm 6.03$ & $96.59 \pm 4.55$ \\
\hline TT 3 & $29.58 \pm 7.15$ & $162.48 \pm 08.54$ & $34.33 \pm 5.32$ & $96.48 \pm 2.47$ \\
\hline TT 4 & $14.59 \pm 6.97$ & $109.43 \pm 09.45$ & $83.00 \pm 6.07$ & $95.88 \pm 3.89$ \\
\hline TT 5 & $14.35 \pm 4.05$ & $121.55 \pm 15.87$ & $61.50 \pm 5.54$ & $95.52 \pm 4.07$ \\
\hline TT 6 & $16.23 \pm 3.18$ & $118.56 \pm 11.87$ & $74.50 \pm 5.68$ & $96.32 \pm 3.89$ \\
\hline TT 0 & $15.94 \pm 6.14$ & $146.54 \pm 10.92$ & $35.00 \pm 6.07$ & $101.56 \pm 4.53$ \\
\hline
\end{tabular}

*Data are expressed as mean \pm SD

\section{In vitro drug dissolution studies}

These tablets of tacrolimus are to be applied under the tongue, where they come in contact with the highly vascularized mucosa and consequently, once dissolved, the drug will be completely absorbed.
Therefore, fast disintegration, as well as moderately fast dissolution, is necessary so that the dose is not swallowed into the stomach. The greater the percentage dissolution the better it indicates that the tablet dissolves faster and absorbs faster too. The dissolution behaviour of tablets was investigated and is presented in fig. 8 and fig. 9 .

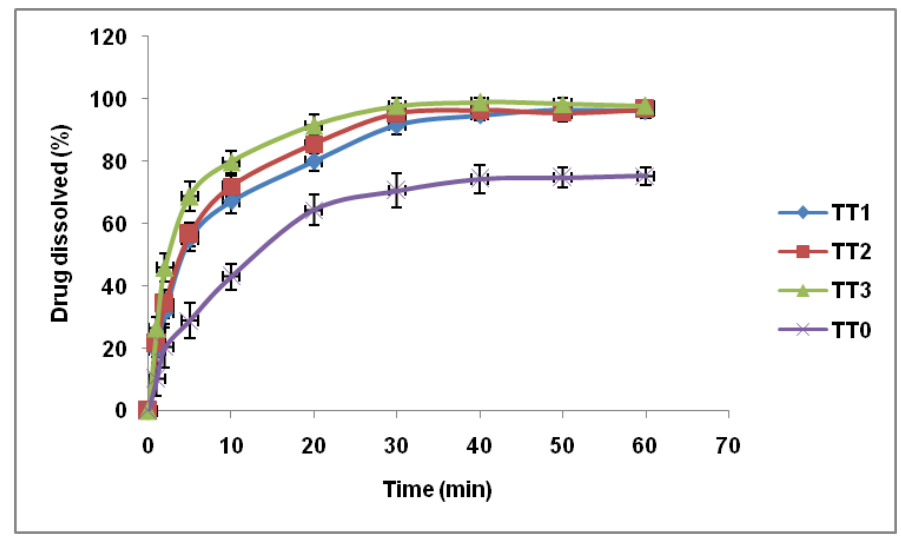

Fig. 8: In vitro drug dissolution studies of sublingual tablets (TT0 and TT1-TT3), data are expressed as mean values with SD error bars (n=3)

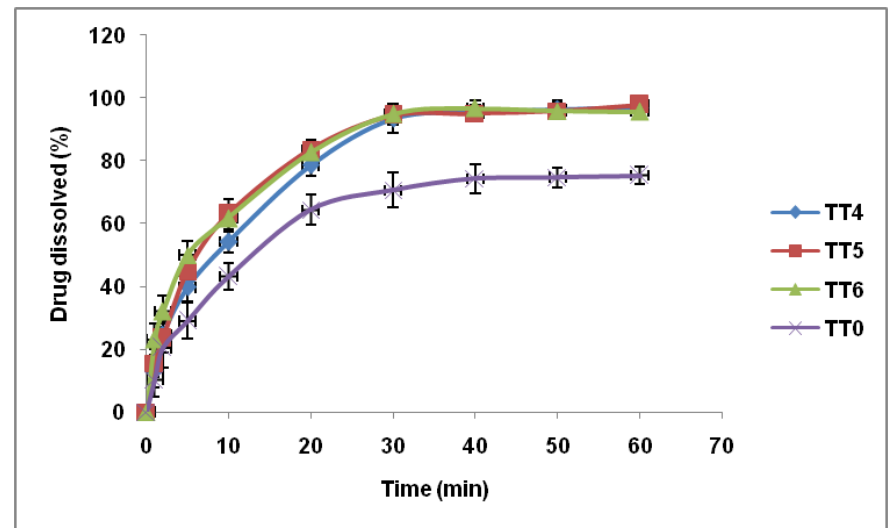

Fig. 9: In vitro drug dissolution studies of sublingual tablets (TT0 and TT4-TT6), data are expressed as mean values with SD error bars (n=3) 
A slightly higher dissolution rate was obtained for tablets prepared with CCS as disintegrant compared to those manufactured with SSG. As discussed earlier this may be due to the gel layer formation associated with SSG which also delayed disintegration. At $20 \mathrm{~min}$, almost all the tablet formulations released more than $80 \%$ of the drug. Apart from the contribution of superdisintegrants (CCS and SSG), faster dissolution of the drug from the formulations is also aided by the addition of sodium lauryl sulphate, a water-soluble surface-active agent which speeds up the tablet's disintegration.

The inclusion complex loaded tablets showed a greater release of the drug compared to the slow dissolution of pure tacrolimus loaded tablets. This result confirms that the partially amorphous drug in the inclusion complex yielded a higher dissolution rate than the crystalline drug in tablets.

Among the formulation batches prepared TT3 was considered to be the optimized formula because of its better performance in vitro disintegration time (34.33 s) as well as dissolution evaluations (percent drug release of 97.87).

\section{CONCLUSION}

Due to the poor in vivo pharmacokinetic performance of tacrolimus with respect to dissolution and bioavailability aspects, the successful delivery of this lipophilic candidate presents challenges to researchers. Overcoming these problems may prove to be a boon to patients both from a therapeutic as well as economic point of view because it is a costly drug too. In this research work, an effort to increase the aqueous solubility of tacrolimus was made by converting it to inclusion complexes with $\beta$-cyclodextrin by utilizing the kneading method which is a quite easy process due to the lack of specialized techniques. The complexation led to changes in crystallinity and partial conversion to the amorphous form of the medicine and improved the aqueous solubility to a greater extent compared to that of the pure drug. The tablet formulations prepared were all fast disintegrating in nature, with the inclusion complex loaded tablets showing better dissolution profiles compared to pure drug tablets. As the safety and efficacy of sublingual tacrolimus are already proved, this tablet formulation is therefore proposed for sublingual administration and further clinical pharmacokinetic studies.

\section{ACKNOWLEDGEMENT}

Thanking College of Pharmaceutical Sciences, Govt. Medical College, Kozhikode, Kerala, India for the facilities given for doing this research work.

\section{FUNDING}

Nil

\section{AUTHORS CONTRIBUTIONS}

All the authors have contributed equally.

\section{CONFLICT OF INTERESTS}

The authors declare no conflict of interest.

\section{REFERENCES}

1. Park YJ, Ryu DS, Li DX, Quan QZ, Oh DH, Kim JO, Seo YG, Lee YI, Yong CS, Woo JS, Choi HG. Physicochemical characterization of tacrolimus-loaded solid dispersion with sodium carboxylmethyl cellulose and sodium lauryl sulfate. Arch Pharm Res. 2009;32(6):893-8. doi: 10.1007/s12272-009-1611-5, PMID 19557367.

2. Tamura S, Ohike A, Ibuki R, Amidon GL, Yamashita S. Tacrolimus is a class II low-solubility high-permeability drug: the effect of P-glycoprotein efflux on regional permeability of tacrolimus in rats. J Pharm Sci. 2002;91(3):719-29. doi: 10.1002/jps.10041, PMID 11920757.

3. Joint formulary committee. British National Formulary. BMJ 2008;56:483.

4. Van Duijnhoven E, Christiaans M, Undre N, Stevenson P, Van Hooff J. The effect of breakfast on the oral bioavailability of tacrolimus in diabetic and nondiabetic patients before transplantation. Transplant Proc. 1998;30(4):1268-70. doi: 10.1016/s0041-1345(98)00237-1, PMID 9636515.
5. Patel P, Patel H, Panchal S, Mehta T. Formulation strategies for drug delivery of tacrolimus: an overview. Int J Pharm Investig. 2012;2(4):169-75. doi: 10.4103/2230-973X.106981, PMID 23580932.

6. Srinarong P, Pham BT, Holen M, Van Der Plas A, Schellekens RCA, Hinrichs WLJ, Frijlink HW. Preparation and physicochemical evaluation of a new tacrolimus tablet formulation for sublingual administration. Drug Dev Ind Pharm. 2012;38(4):490-500. doi: 10.3109/03639045.2011.613075, PMID 21961909.

7. Zidan AS. Taste-masked tacrolimus-phospholipid nanodispersions: dissolution enhancement, taste masking and reduced gastric complications. Pharm Dev Technol. 2017;22(2):173-83. doi: 10.3109/10837450.2016.1138131, PMID 26811031.

8. Chung Y, Cho H. Preparation of highly water soluble tacrolimus derivatives: poly(ethylene glycol) esters as potential prodrugs. Arch Pharm Res. 2004;27(8):878-83. doi: 10.1007/BF02980183, PMID 15460452.

9. Yamashita K, Nakate T, Okimoto K, Ohike A, Tokunaga Y, Ibuki R, Higaki K, Kimura T. Establishment of new preparation method for solid dispersion formulation of tacrolimus. Int J Pharm. 2003;267(1-2):79-91. doi: 10.1016/j.ijpharm.2003.07.010, PMID 14602386.

10. Yoshida T, Kurimoto I, Yoshihara $\mathrm{K}$, Umejima $\mathrm{H}$, Ito $\mathrm{N}$, Watanabe S. Aminoalkyl methacrylate copolymers for improving the solubility of tacrolimus. I: Evaluation of solid dispersion formulations. Int J Pharm. 2012;428(1-2):18-24 doi: 10.1016/j.ijpharm.2012.02.041, PMID 22405967.

11. Kovvasu SP, Kunamaneni P, Kunderu RS. Cyclodextrins and their application in enhancing the solubility, dissolution rate and bioavailability. Innoriginal Int J Sci 2018;5:25-34.

12. Al Sagheer T, Enderby CY. Determining the conversion ratios for oral versus sublingual administration of tacrolimus in solid organ transplant recipients. Clin Transplant. 2019;33(10):e13727. doi: 10.1111/ctr.13727, PMID 31587353.

13. Solari S, Cancino A, Wolff R, Norero B, Vargas JI, Barrera F, Guerra JF, Martínez J, Jarufe N, Soza A, Arrese M, Benitez C. Sublingual tacrolimus administration provides similar drug exposure to per-oral route employing lower doses in liver transplantation: a pilot study. Aliment Pharmacol Ther. 2017;45(9):1225-31. doi: 10.1111/apt.14022, PMID 28261844.

14. Watkins KD, Boettger RF, Hanger KM, Leard LE, Golden JA, Hoopes CW. Use of sublingual tacrolimus in lung transplant recipients. J Heart Lung Transplant. 2012;31(2):127-32. doi: 10.1016/j.healun.2011.10.015, PMID 22177691.

15. Nasiri-Toosi Z, Dashti-Khavidaki S, Nasiri-Toosi M, Khalili $\mathrm{H}$, Jafarian A, Irajian $\mathrm{H}$, Abdollahi A, Sadrai S. Clinical pharmacokinetics of oral versus sublingual administration of tacrolimus in adult liver transplant recipients. Exp Clin Transplant. 2012;10(6):586-91. doi: 10.6002/ect.2012.0032, PMID 22770208.

16. Arima H, Yunomae K, Miyake K, Irie T, Hirayama F, Uekama K. Comparative studies of the enhancing effects of cyclodextrins on the solubility and oral bioavailability of tacrolimus in rats. J Pharm Sci. 2001;90(6):690-701. doi: 10.1002/jps.1025, PMID 11357172.

17. Tacrolimus Revision bulletin. The United States Pharmacopoeia The United States Pharmacopoeial Convention; 2013. p. 3-5.

18. Joe JH, Lee WM, Park YJ, Joe KH, Oh DH, Seo YG, Woo JS, Yong CS, Choi HG. Effect of the solid-dispersion method on the solubility and crystalline property of tacrolimus. Int J Pharm. 2010;395(1-2):161-6. doi: 10.1016/j.ijpharm.2010.05.023, PMID 20580799.

19. Shinkar DM, Aher PS, Kothawade PD, Maru AD. Formulation and in vitro evaluation of fast dissolving tablet of verapamil hydrochloride. Int J Pharm Pharm Sci. 2018;10(10):93-9. doi: 10.22159/ijpps.2018v10i10.28714.

20. Purkayastha HD, Nath B. Formulation and evaluation of oral fast disintegrating tablet of ibuprofen using two super disintegrants. Int J Curr Pharm Sci. 2017;9(4):92-5. doi: $10.22159 / 20966$.

21. Choudhury P, Deb P, Dash S. Formulation and statistical optimization of bilayer sublingual tablets of levocetirizine hydrochloride and ambroxol hydrochloride. Asian J Pharm Clin Res. 2016;9(5):228-34. doi: 10.22159/ajpcr.2016.v9i5.13343. 
22. Lachman L, Lieberman HA Kanig JL. The theory and practice of industrial pharmacy. Lea \& Febiger; 1987. p. 296-301.

23. Tashan E, Karakucuk A, Celebi N. Development of nanocrystal ziprasidone orally disintegrating tablets: optimization by using design of experiment and in vitro evaluation. AAPS PharmSciTech. 2020;21(3):115. doi: 10.1208/s12249-02001653-9, PMID 32296987.

24. Prajapati ST, Patel PB, Patel CN. Formulation and evaluation of sublingual tablets containing sumatriptan succinate. Int J Pharm Investig. 2012;2(3):162-8. doi: 10.4103/2230973X.104400, PMID 23373008.

25. Rawas-Qalaji MM, Simons FE, Simons KJ. Fast-disintegrating sublingual epinephrine tablets: effect of tablet dimensions on tablet characteristics. Drug Dev Ind Pharm. 2007;33(5):523-30. doi: 10.1080/03639040600897150, PMID 17520443.

26. Jaya S, Amala V. Formulation and in vitro evaluation of oral disintegrating tablets of amlodipine besylate. Int J App Pharm. 2019;11(1):49-54. doi: 10.22159/ijap.2019v11i1.28457.
27. Ponnammal P, Kanaujia P, Yani Y, Ng WK, Tan RBH. Orally disintegrating tablets containing melt extruded amorphous solid dispersion of tacrolimus for dissolution enhancement. Pharmaceutics. 2018;10(1):35.

10.3390/pharmaceutics10010035, PMID 29547585

28. Kassem AA, Labib GS. Flash dissolving sublingual almotriptan malate for management of migraine. Int J Pharm Pharm Sci. 2017;9:125-31.

29. Indian pharmacopoeia. Volume II. Government of India Ministry of Health and Family Welfare. The Indian pharmacopoeia commission. Ghaziabad; 2014.

30. Rojas J, Guisao S, Ruge V. Functional assessment of four types of disintegrants and their effect on the spironolactone release properties. AAPS PharmSciTech. 2012;13(4):1054-62. doi: 10.1208/s12249-012-9835-y, PMID 22899380.

31. Tacrolimus capsules revision [bulletin]. The United States pharmacopoeia. The United States pharmacopoeial convention; 2018. p. 1-7. 